\title{
Avaliação do quadro eritrocitário e da repercussão do estado anêmico no leucograma de caprinos com verminose gastrintestinal $^{1}$
}

\author{
Daniela B. Birgel ${ }^{2 *}$, Alois F. Muller², Paulo Fantinato-Neto ${ }^{4}$, Vanessa M. Storillo ${ }^{4}$, \\ Fernando J. Benesi ${ }^{3}$ e Eduardo H. Birgel Junior ${ }^{2}$
}

\begin{abstract}
Birgel D.B., Muller A.F., Fantinato-Neto P., Storillo V.M., Benesi F.J. \& Birgel Junior E.H. 2014. [Evaluation of the erythrocyte pattern and the repercussions of anemic status in white blood cells of goats with gastrointestinal helminthiasis.] Avaliação do quadro eritrocitário e da repercussão do estado anêmico no leucograma de caprinos com verminose gastrintestinal. Pesquisa Veterinária Brasileira 34(3):199-204. Departamento de Medicina Veterinária, Faculdade de Zootecnia e Engenharia de Alimentos, Universidade de São Paulo, Av. Duque de Caxias Norte 225, Campus da USP, Pirassununga, SP 13635-900, Brazil. E-mail: dabirgel@gmail.com

In order to characterize the anemia and its impact over the white blood cell count (WBC) due to gastrointestinal parasitism, cells blood count (CBC) of 96 adult Saanen goats were performed. Fifty-seven of these goats were anemic. The disease diagnosis was based on the characteristic signals of gastrointestinal parasitism (whitened conjunctival mucous, submandibular edema, loss of weight and bristling hair coat), confirmed by the presence of Trichostrongyloidea eggs in the stool test. The blood samples were collected from the jugular vein using an EDTA siliconized tubes with vacuum. Erythrocyte counts, packed cell volume, hemoglobin concentration, blood indices (MCV, MCH and MCHC), total leukocyte counts, and differential leukocyte count were performed. The goats were divided into four groups based on the magnitude of packed cell volume decrease: (1) goats without anemia, (2) mild anemia, (3) moderate anemia, and (4) severe anemia. Normocytic and normochromic anemia were observed in animals with mild to moderate anemia, while in animals with severe anemia (decreased more than half of normal values of $\mathrm{He}, \mathrm{Ht}, \mathrm{Hb}$ ) hypochromic and normocytic anemia was observed. The total number of leukocytes did not change, while the anemic state due to gastrointestinal parasitism determined neutrophilia without a left shift, monocytosis and lymphopenia absolute. It was observed a change of the pattern leukocyte count, which becoming mostly neutrophilic. This reversal was more pronounced as the anemic process became more intense.
\end{abstract}

INDEX TERMS: Gastrointestinal helminthiasis, anemia, erythrocyte pattern, goats, Haemonchus, WBC.

RESUMO.- Com o intuito de caracterizar a anemia decorrente da verminose gastrintestinal e avaliar as alterações no leucograma, foram realizadas hemogramas de 96 capri-

\footnotetext{
${ }^{1}$ Recebido em 30 de setembro de 2013.

Aceito para publicação em 17 de dezembro de 2013.

${ }^{2}$ Departamento de Medicina Veterinária, Faculdade de Zootecnia e Engenharia de Alimentos (FZEA), Av. Duque de Caxias Norte 225, Campus da USP, Pirassununga, SP 13635-900, Brasil. *Autor para correspondência: dabirgel@gmail.com

${ }^{3}$ Departamento de Clínica Médica, Faculdade de Medicina Veterinária e Zootecnia (FMVZ), Universidade de São Paulo (USP), Av. Prof. Dr. Orlando Marques de Paiva 87, Cidade Universitária, São Paulo, SP 05508-270, , SP 13635-900, Brasil.

${ }^{4}$ Departamento de Cirurgia, FMVZ-USP, São Paulo, SP.
}

nos da raça Saanen adultos, sendo que 57 destes estavam anêmicos. 0 diagnóstico da enfermidade foi realizado pelos sintomas característicos da doença como mucosas conjuntival esbranquiçadas, edema submandibular, emagrecimento e pelame arrepiado, confirmados por exame de fezes no qual se detectou a presença de ovos da superfamília Trichostrongyloidea. As amostras de sangue foram colhidas por punção da veia jugular, utilizando-se o EDTA como anticoagulante. Realizaram-se as seguintes provas: contagem do numero de hemácias, determinação do volume globular, dosagem de hemoglobina, cálculo dos índices hematimétricos (VCM, HCM e CHCM), contagem do número total de leucócitos e a contagem diferencial de leucócitos, efetuada em esfregaços sanguíneos, corados pelo método de Rosen- 
feld. Os animais foram divididos em grupos, baseado na magnitude da diminuição do volume globular, (1) animais sem anemia, (2) anemia de grau leve, (3) anemia moderada e (4) anemia intensa. Nos processos anêmicos leves ou moderados a anemia era do tipo normocítico e normocrômico, enquanto nos animais com anemia intensa (diminuição maior que metade dos valores normais de $\mathrm{He}, \mathrm{Ht}, \mathrm{Hb}$ ) observou-se anemia do tipo normocítico e hipocrômico. 0 estado anêmico decorrente da verminose gastrintestinal determinou normoleucocitemia, neutrofilia sem desvio a esquerda, monocitose e linfopenia absoluta. Observou-se inversão do padrão leucocitário, que passou de linfocitário para neutrofílico. Essa inversão acentuou-se à medida que a gravidade da anemia verminótica tornava-se mais intensa.

TERMOS DE INDEXAÇÃO: Helmintose gastrintestinal, anemia, verminose gastrintestinal, caprinos, Haemonchus, leucograma.

\section{INTRODUÇÃO}

Na região sudeste do Brasil, os nematódeos de maior importância para os pequenos ruminantes são: Haemonchus contortus, Trichostrongylus colubriformis, Strongyloides spp., Cooperia curticei e Oesophagostomum columbianum (Amarante et al. 1997, Amarante et al. 2004). Pelas condições climáticas nessa região considera-se que o Haemonchus contortus desempenha papel principal (Lopes et al. 1997, Vieira Bressan et al. 1995). Em pesquisa realizada no Estado de São Paulo verificou-se que $64 \%$ das larvas cultivadas e identificadas em amostras de fezes obtidas de animais com verminose eram deste gênero de parasita (Faria Junior et al., 2002).

Blood, Henderson \& Radostitis (1988) ressaltaram que a ingestão de grandes quantidades de larvas de Haemonchus contortus pode levar a hemoncose hiperaguda em cordeiros, ocorrendo, num prazo de sete dias, morte súbita. As infestações crônicas envolvendo números menores de helmintos determinaram alterações caracterizadas por anorexia, menor ganho de peso, emagrecimento progressivo, ausência de diarreia e anemia (Ruas \& Berne, 2001). Em caprinos acometidos de intensa helmintose gastrintestinal (mais de 2.000 ovos por grama de fezes) a presença de mucosas esbranquiçadas foi observada em $23,33 \%$ dos animais e ocorrência de edemas em 3,33\% das cabras examinadas (Faria Junior et al. 2002). 0 edema que se instala nos quadros de hemoncose ocorre em consequência a hipoproteinemia e hipoalbuminemia (Abbott, Parkins \& Holmes, 1988, 1984), enquanto a anemia é causada principalmente pela ação hematófaga do Haemonchus contortus (Garcia \& D'Angelino 1985), sendo estimado que cada parasito deste gênero sugue $0,05 \mathrm{ml}$ de sangue por dia (Ruas \& Berne 2001).Nos estados anêmicos pode ser observado taquipneia, respiração superficial e dispnéia, bem como alterações do sistema cardiovascular, caracterizado por taquicardia com sopros cardíacos sistólicos, orelhas e extremidades frias (Benesi 1985, Birgel, 1999).

A ocorrência de anemia macrocítica ou de anemia normocítica e normocrômica foi relatada em associação com a infecção de ovinos por Haemonchus contortus (Abbott, Parkins \& Holmes, 1984; Faria Junior et al., 2002). Em estudo realizado em caprinos. Garcia et al. (1983) observaram as seguintes características morfológicas das anemias decorrentes da verminose gastrintestinal: $72 \%$ dos casos do tipo macrocítico, $23 \%$ dos casos do tipo normocítico e $78 \%$ casos normocrômicas e 18 \% dos casos hipocrômicas.

A verminose gastrintestinal nos pequenos ruminantes é responsável por significativa redução da produtividade, aumento da mortalidade e perdas econômicas (Gennari \& Amarante, 2006). Desta forma justificam-se pesquisas que tenham como objetivo detalhar melhor as alterações que a anemia verminótica determina no hemograma. Dentro deste raciocínio o objetivo desta pesquisa foi caracterizar o tipo de anemia segundo a sua intensidade, e determinar a repercussão da gravidade da anemia verminótica sobre o leucograma de caprinos, esperando contribuir para o melhor entendimento clínico desta enfermidade.

\section{MATERIAL E MÉTODOS}

Os dados apresentados são oriundos de atendimentos de caprinos enfermos realizados na Unidade Didático Clínico Hospitalar em Medicina Veterinária da FZEA / USP, localizada em Pirassununga/SP (região centro-leste do Estado de São Paulo, latitude $21^{\circ} 59^{\prime} 46^{\prime \prime}$ Sul e longitude $7^{\circ} 25^{\prime} 33^{\prime \prime}$ Oeste) e pela clínica ambulante em propriedades situadas num raio de $200 \mathrm{Km}$ da sede do Unidade Hospitalar. Foram utilizadas propriedades com histórico de problemas de verminose gastrintestinal, nas quais verificou-se, por meio de necropsia, que as infecções eram determinadas, principalmente, por Haemonchus contortus. A seleção dos animais utilizados no experimento foi feita por exame clínico que assegurasse a existência do estado anêmico, sendo o diagnóstico de verminose gastrintestinal decorrente à infecções por parasitas da superfamília Trichostrongyloidea, confirmado por meio de exame coproparasitológico - pela técnica de flutuação utilizando solução hipersaturada de cloreto de sódio. A presença de anemia foi confirmada por meio da determinação do volume globular.

No total foram utilizados 96 caprinos adultos da raça Saanen, sendo que 57 apresentavam quadro de anemia decorrente à verminose gastrintestinal. Os 57 animais com anemia verminótica eram de propriedades nas quais observou-se por necropsia a ocorrência de verminose gastrintestinal por Haemonchus contortus. 0 diagnóstico da enfermidade foi realizado pelos sintomas característicos da doença, como mucosas conjuntival esbranquiçadas, edema submandibular, emagrecimento e pelame arrepiado, confirmados por exame de fezes, no qual detectou-se a presença de ovos da superfamília Trichostrongyloidea.

As amostras para hematimetria foram colhidas por punção da veia jugular externa em tubos de vidro siliconizados contendo $0,05 \mathrm{ml}$ de uma solução aquosa de etilenodiamino-tetracética-dissódica (EDTA) a 10\% e com vácuo suficiente para aspirar $5 \mathrm{ml}$ de sangue (BD Vacutainer ${ }^{\circledR}$ ), sendo mantidas refrigeradas até $o$ momento da realização dos exames, sempre concluídos antes de decorridas 24 horas de conservação.

A contagem do número de hemácias foi realizada em Câmara de Neubauer modificada, sendo as amostras de sangue diluídas, em pipeta hematimétrica específica, na proporção de 1:200, utilizando-se como solução diluidora o líquido de Gower; a determinação do volume globular foi realizada pelo método do microhematócrito e a dosagem de hemoglobina pelo método que transforma a hemoglobina em cianometahemoglobina; sendo a seguir calculados os valores dos índices hematimétricos absolutos de volume corpuscular médio (VCM), hemoglobina corpuscular média (HCM) e concentração hemoglobínica corpuscular média (CHCM) de acordo com as recomendações de Birgel (1982). 
A contagem do número total de leucócitos foi realizada em Câmara de Neubauer modificada, sendo as amostras de sangue diluídas, em pipeta hematimétrica específica, na proporção de 1:20, utilizando-se como solução diluidora o líquido de Thoma de acordo com as recomendações de Birgel (1982). Para a contagem diferencial de leucóctios foram distendidos dois esfregaços sanguíneos com o sangue "in natura", corados com o corante de Rosenfeld, segundo técnica padronizada para os animais por Birgel (1982). Em cada esfregaço sanguíneo foram diferenciados 100 leucócitos e classificados de acordo com suas características morfológicas e tintoriais, em neutrófilos com núcleo em bastonete, neutrófilos com núcleo segmentado; eosinófilos, basófilos, linfócitos e monócitos.

A contagem do número de ovos de nematóides gastrintestinais foi realizada pela técnica de flutuação utilizando solução hipersaturada de cloreto de sódio, sendo a contagem do número de ovos por grama de fezes (OPG) realizada em Câmara de Macmaster, de acordo com as recomendações de Ueno \& Gonçalves (1998).

Baseado na magnitude da diminuição do volume globular os animais foram divididos nos seguintes grupos experimentais: animais sem anemia, anemia de grau leve, anemia moderada e anemia intensa (Quadro 1).

A análise estatística foi realizada utilizando o programa SAS/ STAT $^{\circledR}$ software System for Windows (SAS, 2000). Os dados foram submetidos à análise de variância, utilizando-se o comando "PROC GLM", sendo o contraste das médias analisado pelo Teste $\mathrm{t}$ de Student, com níveis de significância igual a $5 \%(\mathrm{p} \leq 0,05)$. A pesquisa foi desenvolvida dentro dos princípios de ética animal e aprovado pela Comissão de Ética no Uso de Animais da Faculdade de Zootecnia e Engenharia de Alimentos da Universidade de São Paulo (Proc. 13.1.2788.74.2).

Quadro 1. Constituição dos grupos experimentais para avaliar o quadro eritrocitário e a repercussão da anemia verminótica no leucograma

\begin{tabular}{|c|c|c|c|}
\hline Grupos & Intensidade da anemia & $\begin{array}{l}\text { Número de } \\
\text { animais }\end{array}$ & OPG \\
\hline 1 & $\begin{array}{l}\text { Caprinos com anemia intensa } \\
\text { Volume globular variando entre } 7 \text { e } 12 \%\end{array}$ & 14 & $8407 \pm 1305^{a}$ \\
\hline 2 & $\begin{array}{l}\text { Caprinos com anemia moderada } \\
\text { Volume globular variando entre } 14 \text { e } 21 \%\end{array}$ & 14 & $1750 \pm 2818^{b}$ \\
\hline 3 & $\begin{array}{l}\text { Caprinos com anemia leve } \\
\text { Volume globular variando entre } 22 \text { e } 25 \%\end{array}$ & 29 & $1183 \pm 1975^{b}$ \\
\hline 4 & $\begin{array}{l}\text { Caprinos sem anemia } \\
\text { Volume globular variando entre } 28 \text { e } 35 \%\end{array}$ & 39 & $0 \pm 0^{c}$ \\
\hline
\end{tabular}

abc Letras diferentes significam diferença estatística significante, Teste de Kruskal-Wallis $(\mathrm{p} \leq 0,05)$.

\section{RESULTADOS}

Nas Figuras 1, 2 e 3 são apresentados os resultados do número de hemácias, do volume globular e da taxa de hemoglobina de caprinos com anemia de diversos graus e animais sem anemia, permitindo a caracterização da intensidade da anemia de cada sub-grupo experimental.

Nas Figuras 4, 5 e 6 são apresentados os índices hematimétricos absolutos observados nos quatro sub-grupos experimentais (anemia intensa, anemia moderada, anemia leve e sem anemia). Depreende-se da análise dos resultados que a classificação da anemia varia de acordo com a intensidade do processo anêmico, de forma que nos processos leves ou moderados a anemia era do tipo normocítico e normocrô- mico, enquanto nos animais com anemia grave, a classificação observada era do tipo normocítico e hipocrômico.

A avaliação da repercussão do estado anêmico/verminose gastrintestinal sobre o leucograma evidenciou normoleucocitemia com existência de neutrofilia sem desvio a esquerda, monocitose e linfopenia absoluta (Fig.7-12).

Na presente pesquisa, leucocitose (animais com mais de

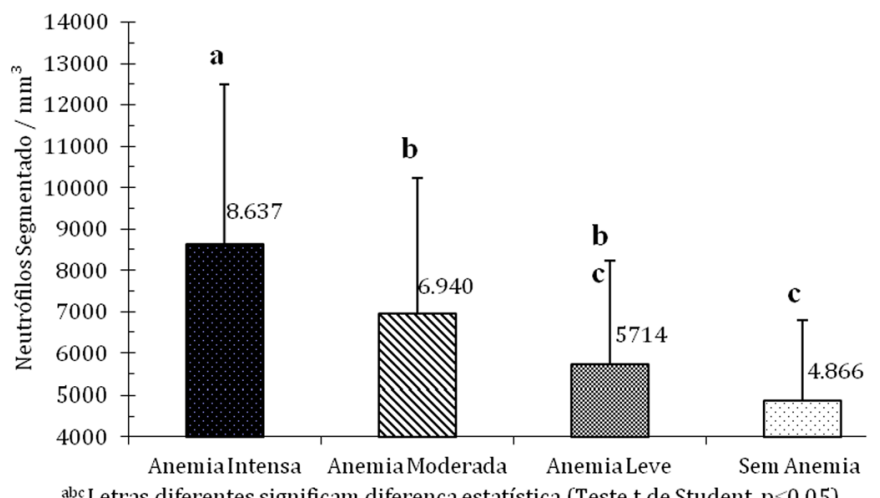

Fig.1. Número de hemácias de caprinos distribuídos segundo o grau de anemia.

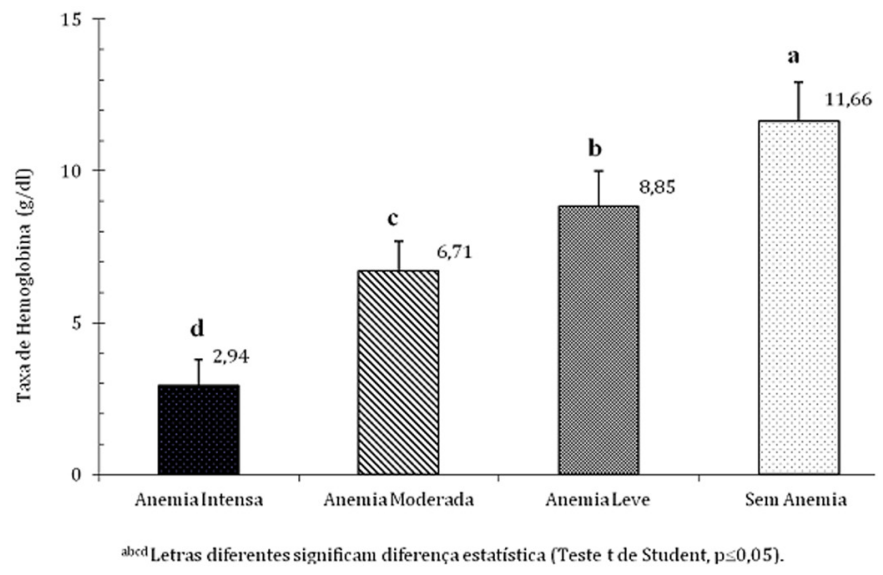

Fig.2. Taxa de Hemoglobina de caprinos distribuídos segundo o grau de anemia.

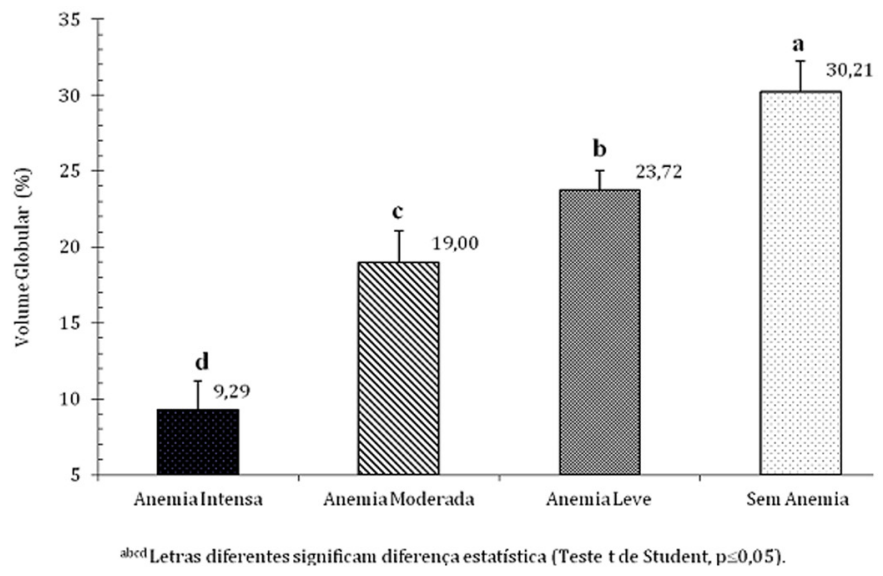

Fig.3. Volume Globular de caprinos distribuídos segundo o grau de anemia. 


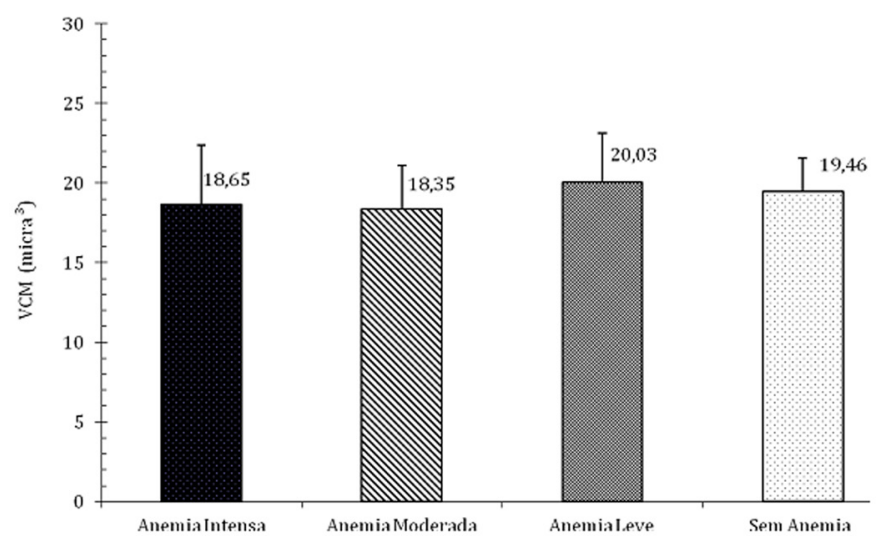

Fig.4. Volume Corpuscular Médio de caprinos distribuídos segundo o grau de anemia.

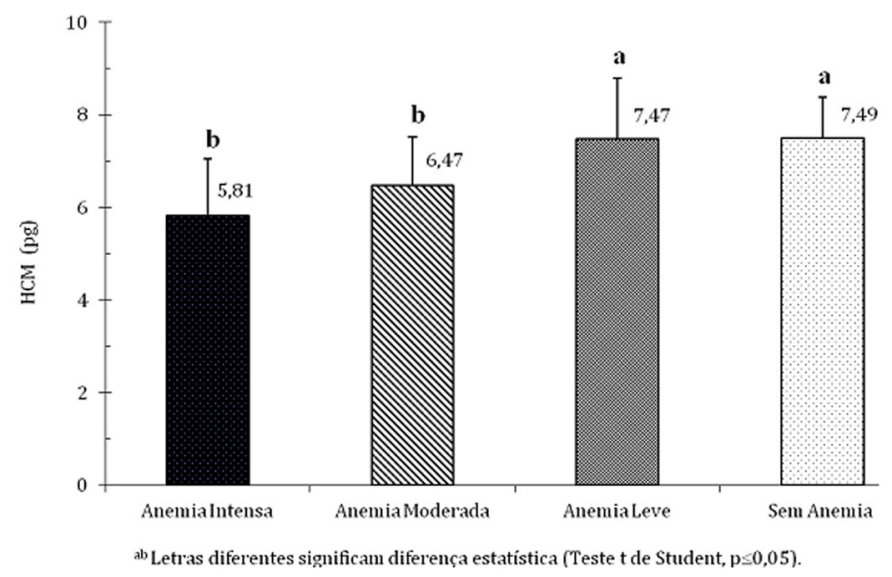

Fig.5. Hemoglobina Corpuscular Médio de caprinos distribuídos segundo o grau de anemia.

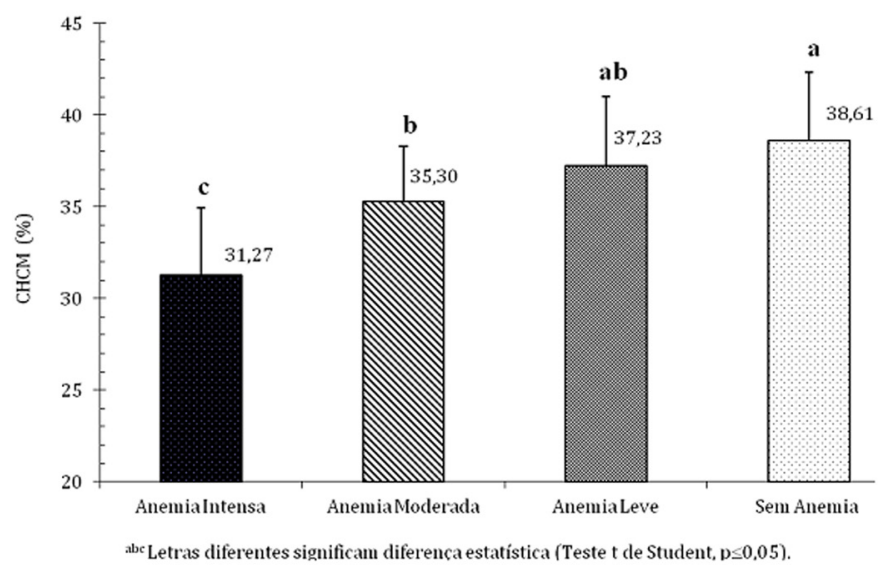

Fig.6. Concentração de Hemoglobina Corpuscular Médio de caprinos distribuídos segundo o grau de anemia.

15.000 leucócitos $\left./ \mathrm{mm}^{3}\right)$ foi observada em $28,6 \%(4 / 14)$ dos caprinos com anemia intensa, em 21,4\% (3/14) dos caprinos com anemia moderada e 6,9\% (2/29) dos caprinos com anemia leve. No grupo de animais controle (sem anemia) observou-se leucocitose em 2,6\% (1/39) dos animais examinados. Conforme mostram os resultados na Figura 7, a neutrofilia aumentou conforme aumentava a intensidade do processo anêmico.

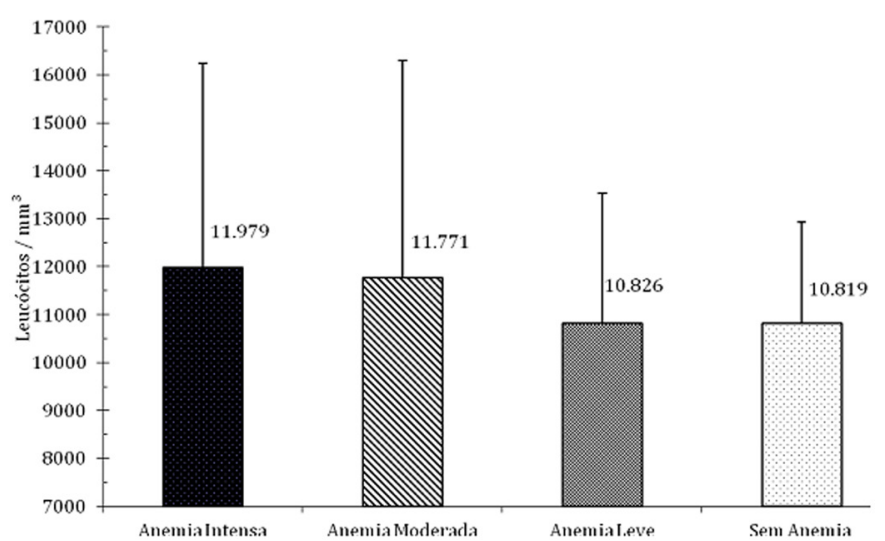

Fig.7. Avaliação da influência do estado anêmico no número total de leucócitos.

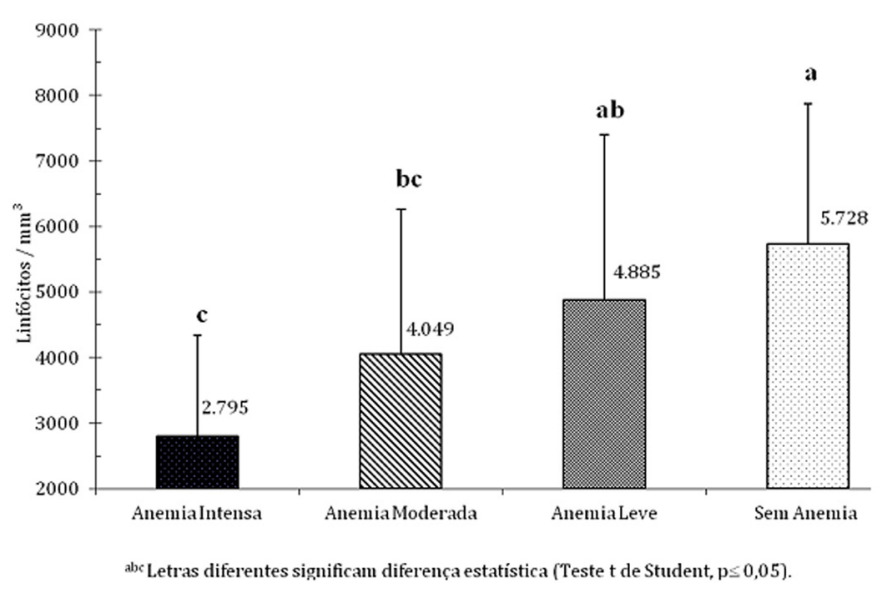

Fig.8. Avaliação da influência do estado anêmico no número absoluto de linfócitos.

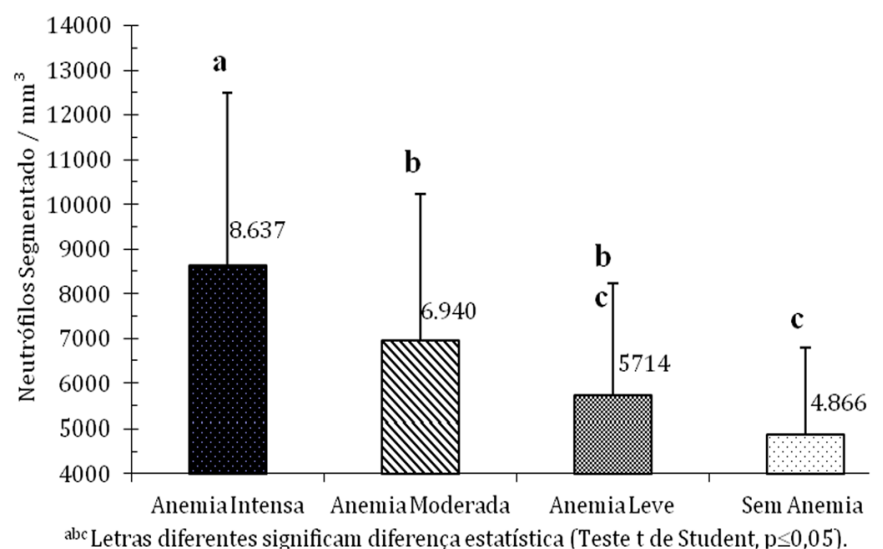

Fig.9. Avaliação da influência do estado anêmico no número absoluto de neutrófilos.

Desvio a esquerda foi fato pouco frequente, sendo que somente em 7,0\% (4/57) dos animais anêmicos encontrou-se mais do que 100 neutrófilos do tipo bastonete $/ \mathrm{mm}^{3}$. No grupo controle observou-se que $25,1 \%$ (9/39) dos animais apresentavam número absoluto de neutrófilos em bastonete maior do que 100 células $/ \mathrm{mm}^{3}$. Animais com mais de 500 neutrófilos bastonete $/ \mathrm{mm}^{3}$ não foram observados em nenhum dos animais examinados. 


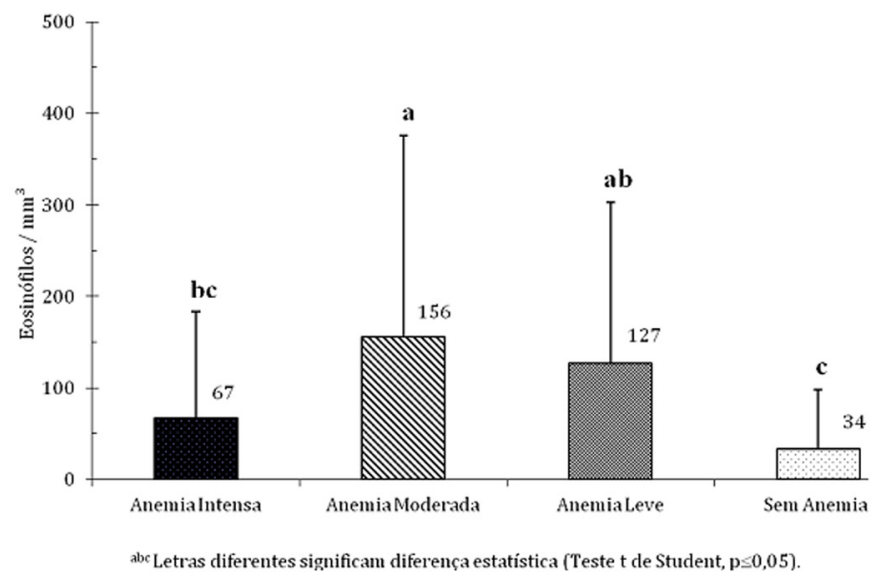

Fig.10. Avaliação da influência do estado anêmico no número absoluto de eosinófilos.

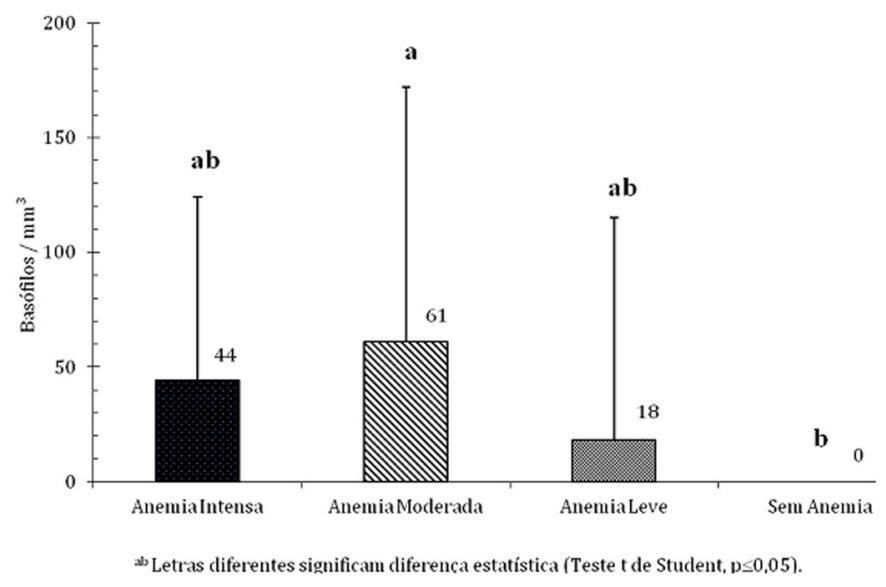

Fig.11. Avaliação da influência do estado anêmico no número absoluto de basófilos.

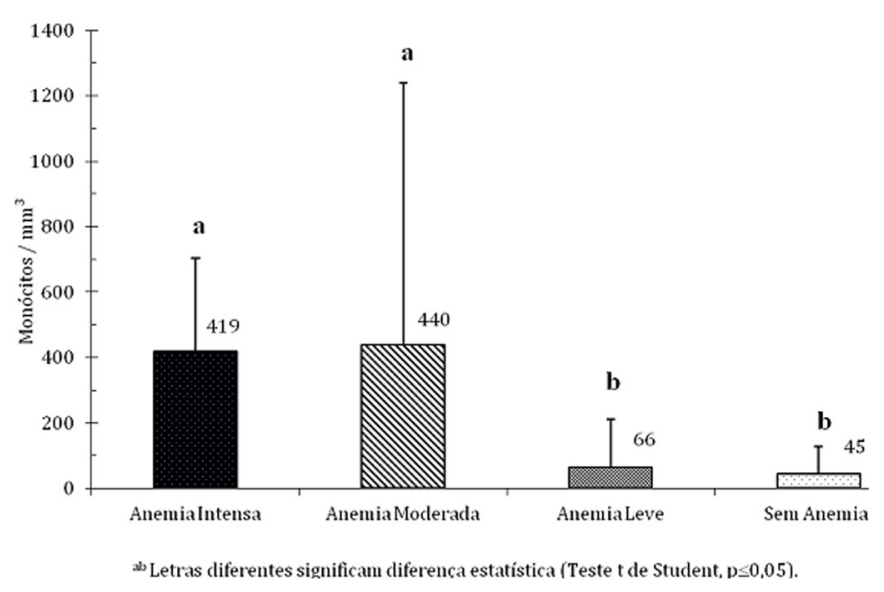

Fig.12. Avaliação da influência do estado anêmico no número absoluto de monócitos.

Observou-se linfopenia absoluta que aumentou conforme a intensidade do processo anêmico (Fig.9) e ocorria inversão do padrão leucocitário, que passa de predominantemente linfocitário para neutrofílico. Essa inversão acentuou-se à medida que o processo anêmico torna-se mais intenso. Nos caprinos sem anemia 38,5\% (15/39) dos animais apresentavam quadro leucocitário predominan- temente neutrofílico. Nos animais com anemia leve esse percentual era de $48,2 \%(14 / 29)$, nos animais com anemia moderada o percentual foi de $57,1 \%$ (8/14), enquanto nos animais com anemia grave o padrão leucocitário foi neutrofílico em 100\% (14/14) dos animais examinados.

\section{DISCUSSÃO}

Ao compulsar-se a literatura sobre anemia de pequenos ruminantes foi descrita, em associação a verminose de pequenos ruminantes por Haemonchus contortus, a ocorrência de anemia macrocítica (Garcia et al. 1983, Abbott et al. 1988,), anemia normocítica e normocrômica (Garcia et al. 1983, Abbott et al. 1984, Faria Junior et al. 2002) ou hipocrômicas (Garcia et al. 1983). Entretanto não foi estabelecida a relação entre o tipo de anemia e a sua intensidade. As discrepâncias relacionadas à classificação do tipo de anemias observadas na literatura compulsada, bem como as observadas na presente pesquisa, devem ser justificadas como inerentes a fase de evolução do processo anêmico. Em processos verminóticos agudos com grave perda de sangue, a medula óssea estimulada pela condição anêmica libera grande quantidade de células jovens e imaturas com maior volume corpuscular médio determinando macrocitose. Conforme o processo cronifica-se, ocorre hiperplasia medular compensatória da anemia, retorna o tecido mieloide a liberar eritrócitos maduros, ocorrendo, então, normocitose e normocromia. Caso o processo de espoliação determinada pelo endoparasita se prolongue e resulte em perdas continuadas de sangue poderá ocorrer depleção das reservas de ferro e consequentemente a anemia torna-se hipocrômica e, finalmente, microcítica. Segundo Birgel (1999), as anemias microciticas, hipocrômicas ou não, são as formas clínicas mais frequentemente diagnosticadas nos pequenos ruminantes, sendo diferenciadas duas formas: anemias microcíticas ferroprivas e anemias microcíticas não ferroprivas. Na primeira forma, além das características hematimétricas, observa-se significativa diminuição das concentrações plasmáticas de ferro; ao passo que na segunda a sideremia coloca seus valores na amplitude de variações fisiológicas. Nessa última forma, o estado de sub-nutrição determinaria déficit proteico e impediria a formação da hemoglobina, por não haver condições de síntese da globulina, mesmo que haja quantidades suficientes de ferro.

A ocorrência de leucocitose por neutrofilia com desvio à esquerda em processos hemorrágicos agudos e intensos poderia ser justificada como consequência ao estímulo mielóide para reestabelecer o número de hemácias circulantes. Entretanto mesmo nas infecções graves por vermes hematófagos, nas quais existissem de 2000 a 5000 Haemonchus contortus, as perdas sanguíneas diárias oscilariam entre 100 e $250 \mathrm{ml}$, não permitindo caracterizar perda aguda de sangue.

Acredita-se que a neutrofilia seja decorrente do processo inflamatório na mucosa do abomaso determinado pelos parasitas gastrintestinais. 0 fato de desvio à esquerda ser pouco frequente em casos de anemias verminóticas indicariam que houve tempo suficiente para ocorrer hiperplasia medular compensatória. Desta forma, o tecido mielóide liberaria somente neutrófilos maduros, justificando a 
neutrofilia sem desvio à esquerda. Outra explicação para a ausência de desvio a esquerda seria a existência de hemograma de estresse decorrente a infecção parasitária. Situações de estresse fisiológico em caprinos, como a parição (Birgel Junior et al. 2005), ou decorrentes ao transporte dos animais, tem sido relacionadas ao aumento da secreção de hormônios do córtex adrenal com liberação endógena de ACTH e ocorrência de leucocitose por neutrofilia sem desvio a esquerda. A monocitose indicaria boa resposta orgânica e é alteração hematológica que pode ser justificada como decorrente a resposta orgânica a reação de estresse ou estar relacionada a fase de evolução do processo infeccioso, na qual durante a fase monocitária defensiva o organismo se defende energicamente da infecção

Entretanto a ausência de leucocitose nos animais avaliados evidencia que no caso das anêmicas crônicas por verminose gastrintestinal existem outros mecanismos que não somente resposta ao estímulo mielóide ou presença de hemograma de estresse para justificar o quadro leucocitário.

Apesar dos mecanismos de imunidade ao parasitismo por Haemonchus contortus ainda não estarem completamente elucidados, pesquisas tem demonstrado o envolvimento dos linfócitos Th2 CD4+ na resposta imune a infecções parasitárias por nematoides (Amarante \& Amarante 2003). Estudos realizados com canulação do abomaso evidenciaram a participação de linfócitos agindo diretamente na mucosa afetada (Schallig, 2000), a ativação e proliferação dos leucócitos em especial os linfócitos (De Veer et al. 2007) e significativa correlação inversa entre a contagem de linfócitos $\mathrm{T}$ na mucosa abomasal e a fecundidade, tamanho e a sobrevivência da fêmea adulta de Haemonchus contortus (Rowe et al. 2008). Esses fatos permitem supor que a diminuição do número de linfócitos circulantes seria consequência da sua provável migração para a mucosa abomasal. Desta forma explicar-se-ia a normoleucocitemia acompanhada de neutrofilia sem desvio a esquerda e linfopenia absoluta observadas nas anemias verminóticas.

Ocorrência de eosinofilia na mucosa abomasal e intestinal foi observada nas infecções por parasitas gastrintestinais e associada a maior resistência às infecções parasitárias. Correlacionou-se a ocorrência do aumento do número de eosinófilos circulantes com baixos valores de opg nas fezes de ovinos e relacionou-se esse fenômeno com maior resistência animal a infecção parasitária (Hohenhaus et al. 1998).

\section{CONCLUSÕES}

0 estado anêmico decorrente a verminose gastrintestinal determinou normoleucocitemia, neutrofilia sem desvio a esquerda, monocitose e linfopenia absoluta.

Observou-se inversão do padrão leucocitário, que passou de linfocitário para neutrofílico.

Essa inversão acentuou-se à medida que a gravidade da anemia verminótica tornava-se mais intensa.

\section{REFERÊNCIAS}

Abbott E.M., Parkins J.J. \& Holmes P.H. 1984. Studies on the pathophysiology of chronic ovine haemonchosis in Merino and Scottish blackface lambs. Parasitology 89(3):585-96.

Abbott E.M., Parkins J.J. \& Holmes P.H. 1988. Influence of dietary protein on the pathophysiology of haemonchosis in lambs given continuous infections. Res. Vet. Sci. 45:41-9.

Amarante A.F.T. \& Amarante M.R.V. 2003. Breeding sheep for resistance to nematode infections. J. Anim. Vet. Adv. 2:147-161.

Amarante A.F.T., Bagnola J., Amarante M.R.V. \& Barbosa M.A. 1997. Host specificity of sheep and cattle nematodes in Sao Paulo state, Brazil. Vet. Parasitol. 73:89-104.

Amarante A.F.T., Bricarello P.A., Rocha R.A. \& Gennari S.M. 2004. Resistance of Santa Ines, Suffolk and Ile de France sheep to naturally acquired gastrointestinal nematode infections. Vet. Parasitol. 120:91-106.

Benesi F.J. 1985. Diagnóstico e terapia das anemias em carprinos, p.171191. In: D’Angelino J.L. (Ed.), Manejo, Patologia e Clínica de Caprinos. Sociedade Paulista de Medicina Veterinária, São Paulo, SP.

Birgel E.H.1982. Hematologia clínia veterinária, p.2-34. In: Birgel E.H. \& Benesi F.J. (Eds), Patologia Clínica Veterinária. Sociedade Paulista de Medicina Veterinária, São Paulo, SP.

Birgel Jr E.H., Viana R.B., Ayres M.C.C., Benesi F.J., Gomes V. \& Birgel E.H. 2005. Influência da parição e do puerpério no leucograma de caprinos (Capra hircus) da raça Saanen, criados no Estado de São Paulo. Braz. J. Vet. Res. Anim. Sci. 42:347-356.

De Veer M.J., Kemp J.M. \& Meeusen E.N. 2007. The innate host defence against nematode parasites. Parasite Immunol. 29:1-9.

Faria Jr S.P., Silva M.M., Scheibel M., Martins M.F., Rabello P., Bertagnon H.G. \& Garcia M. 2002. Uso da contagem fecal de ovos de nematóides para estimar a condição clínica em caprinos. Ciênc. Vet. Tróp. 5:86-92.

Garcia M. \& D’Angelino J.L. 1985. Parasitoses em Caprinos, p.149-170. In: D’Angelino J.L. (Ed.), Manejo, Patologia e Clínica de Caprinos. Sociedade Paulista de Medicina Veterinária, São Paulo, SP.

Gennari S.M. \& Amarante A.F. T. 2006. Helmintos de ovinos e caprinos. Biológico, São Paulo, 68:13-17.

Hohenhaus M.A., Josey M.J., Dobson C. \& Outteridge P.M. 1998. The eosinophil leucocyte, a phenotypic marker of resistance to nematode parasites, is associated with calm behaviour in sheep. Immunol. Cell Biol. 76:153-8.

Lopes R.S., Vieira Bressan M.C.R. \& Kohayagava A. 1997. Comparação entre patogenia e susceptibilidade de bezerros Nelore e Holandês à infecção experimental com Haemonchus placei (Place, 1893). Arq. Bras. Med. Vet. Zootec. 49:279-290.

Rowe A., Gondro C., Emery D. \& Sangster N. 2008. Genomic analyses of Haemonchus contortus infection in sheep: abomasal fistulation and two Haemonchus strains do not substantially confound host gene expression in microarrays. Vet. Parasitol. 154:71-81.

Ruas J.L. \& Berne M.E.A. 2001. Nematódeos gastrintestinais de bovinos e ovinos, p.89-105 In: Riet-Correa F., Schild A.L., Mendez M.D.C. \& Lemos R.A.A. (Eds), Doenças de Ruminante e Equinos. Vol.2, Varela Editora e Livraria, São Paulo.

SAS 2000. SAS OnlineDoc. SAS Institute Inc., Cary, NC.

Schallig H.D. 2000. Immunological responses of sheep to Haemonchus contortus. Parasitology 120(Suppl.):S63-72.

Vieira Bressan M.C.R., Gennari S.M., Santos Filho J.P. \& Rogero J.R. 1995. Observações fisiopatológicas em bezerros infectados concomitantemente com Cooperia punctata e Haemonchus placei. Arq. Bras. Med. Vet. Zootec. 47:53-64. 